\title{
Analysis of Aircraft Ground Power Cost Based on Different Power Supply Methods
}

\author{
ZHOU Guangjun, PAN Weijun, CHEN Kunming, WANG Zhejun, XIONG Feng \\ Civil Aviation Flight University of China, Guanghan Sichuan, 618307 China \\ email:pandazgj@163.com
}

Keywords: ground-holding; electrical power; ground-holding power supply methods; computer simulation

\begin{abstract}
Too aircraft hold on the ground not only brings inconvenience to passenger travel, but also increases the operation cost of airlines. Power supply equipment mainly includes APU (Auxiliary Power Unit) and $400 \mathrm{~Hz}$ electrical power. According to aircraft ground operational situation, a mathematic model was established based on those different power supply methods. Taking Airbus319 for example, this paper utilize computer simulation quantify the proportion of energy consumption, the flight crew cost and other airlines concerned cost. The result shows, the aircraft ground staying cost may reduce by using ground electrical power supply compared with aircraft carry on APU. This model can be used to refine aircraft ground staying cost structure and quantify delay cost differences in different power supply models. The detail results of the analysis of the proportion of energy consumption accounting in the total cost provide proper cost suggestions for airlines, airports and passengers.
\end{abstract}

\section{Introduction}

In recent years, with the demands of air transportation increasing sharply, the phenomena of flight ground-holding become more and more serious. And the economic loss of ground-holding also presents a trend of increasing. So research of ground-holding flight cost is imperative. Foreign scholar began to research on ground-holding flight and came up with some models and algorithm in the 1980s [1-2]. In 1990s,some Chinese scholars also began to study on this field [3-4]. Though these researches refine the cost of ground-holding, but they don't take consideration of power supply of aircraft. Actually keep supply power to the cabin is an important part of ground-holding flight cost. Usually the aircraft are provided power by APU (Auxiliary Power Unit) or electrical power. But different power supply ways have a directly impact on ground-holding cost. Therefore, according to actual operational circumstance, this paper structures math model of power supply differences of ground-holding aircraft. And this paper can provide proper advice when flight chooses power supply methods.

\section{Structuring model}

The cost of ground-holding is not only related to power supply methods, but also related to the time of ground-holding closely. This paper calculates flight ground-holding cost from the views of the passengers and the airlines.

When the aircraft use APU to supply power, the total cost of flight ground-holding includes economic loss of passengers because of ground-holding and the ground-holding cost of the airlines. The airlines ground-holding cost is consisted of APU fuel consumption, hourly wages of crew, accommodation, refund. Its formula is as follows:

$$
C_{\text {all }}=C_{\text {company }}+C_{\text {passenger }}
$$

Under the circumstance of ground-holding, the airlines ground-holding cost can be defined as follows:

$C_{\text {company }}=C_{\text {crew }}+C_{\text {APU }}+C_{\text {else }}$

The hourly wages vary from different positions. The captain' is the highest, the second is co-pilot. 
And the economic cabin stewards' hourly wages is the lowest. Generally, a crew is consisted of one captain, one co-pilot, one purser and 4 economic stewards.

According to CCAR-93TM [7], when the time from aircraft cabin is closed to taken-off is less than $\mathrm{t}^{\prime}=30$ minutes, this flight is not defined as delay flight. So when $\mathrm{t}<\mathrm{t}^{\prime}, \mathrm{C}_{\text {crew }}$ is not existed.

$$
C_{\text {crew }}=\left\{\begin{array}{lr}
0, & t \leq t^{\prime} \\
\sum N_{i} * F_{i} *\left[\frac{t-30}{60}\right], t \geq t^{r}
\end{array}\right.
$$

When ground-holding, the cost of APU is as follows:

$C_{A P U}=N_{k} * M * t$

As the time goes by, the airlines will provide meals and accommodation in stages. And some passengers will refund in order to take another flight. If the passengers run into bad weather or some other special circumstances, the ground-holding time is more than 2 hours, the airlines will cancel the flight and arrange accommodation.it is calculated as follows:

$$
C_{\text {else }}=\left\{\begin{array}{lr}
0, & t \leq t^{r} \\
P_{E} * N_{P}(1-k)+P_{T} * N_{P} * k, & t \geq t 1 \\
\left(P_{B}+P_{R}\right) * N_{P}(1-k)+P_{T} * N_{P} * k, & t<t 2
\end{array}\right.
$$

The loss of passengers is defines as flight ground-holding time multiply by unit hour time value: $C_{\text {passenger }}=P_{N}(1-k) * x * t$

Except the APU, many domestic airports are equipped with electrical power on the bridge. When the aircraft hold on the ground and access to the bridge, the electrical power can provide power for the aircraft. At this time, cost of ground-holding flight and economic loss of passengers are changed too. Then the total loss of ground-holding flight is as follows:

$C_{\text {all }}^{s}=C_{\text {passenger }}+C_{\text {power }}^{z}+C_{\text {crew }}+C_{\text {eise }}$

Among them, the cost of $400 \mathrm{HZ}$ electrical power:

$$
C_{\text {power }}^{r}=\left\{\begin{array}{c}
\frac{t}{15} * 45, t=(15 n) \mathrm{min} \\
{\left[\frac{t}{15}+1\right] * 45, t \neq(15 n) \min }
\end{array}\right. \text { (n is nonnegative integer) }
$$

\section{The numerical simulation and analysis}

In order to embody differences of two power supply ways when ground-holding, this paper takes the main aircraft as example, and simulate and calculate flight ground-holding cost. It is very representative to take A319 for example, because A319 is one of the main types in China and is also one of the most profitable aircrafts.

\section{Analysis of ground-holding cost trend along with time}

Numerical simulation parameters: taken A319 for example. Under the reasonable PLF (Passenger Load Factor), the number of cabin is 97; $t$ means time, timing starts from the cabin closes by minute. $\mathbb{N}_{\mathrm{k}^{\mathrm{n}}}$ fuel consumption per hour. In terms of A319'APU, the type is GTCP85. And fuel consumption $200 \mathrm{~kg}$ per hour. $\mathrm{P}_{\mathrm{B}}$ : The cost for each person per meal the airline provide for passenger, which is 20 yuan per time; $\mathrm{P}_{\mathrm{T}}$ : the price of ticket when refund which is 750 yuan per ticket. $\mathbb{N}_{\mathrm{i}}$ :the number of different positions in a crew. For A319, the crew has one captain, one co-pilot, one purser, one first class steward and two economic class stewards. $\mathrm{F}_{\mathrm{i}}$ : Hourly wages of captain, co-pilot, purser and stewards in the crew respectively are 300, 200,10,70,55. $P_{\mathrm{R}}$ : Accommodation for each passenger every day the airline provides for passenger, which is 200 yuan per time for everyone. M: the price of fuel, which is 7500 yuan per ton. $\mathrm{K}: 2 \%$, the rate of refund. X: 30 yuan per hour, the labor cost. $\mathrm{N}_{\mathrm{c}}$ : 180 yuan per hour, the price of $400 \mathrm{~Hz}$ electrical power when airport provide power supply service for the airlines.

\section{All the proportion trend along with time}

Along with time, all the proportion of the total cost is changing. This paper can get the trend of 
different part along with time by the computer simulation.
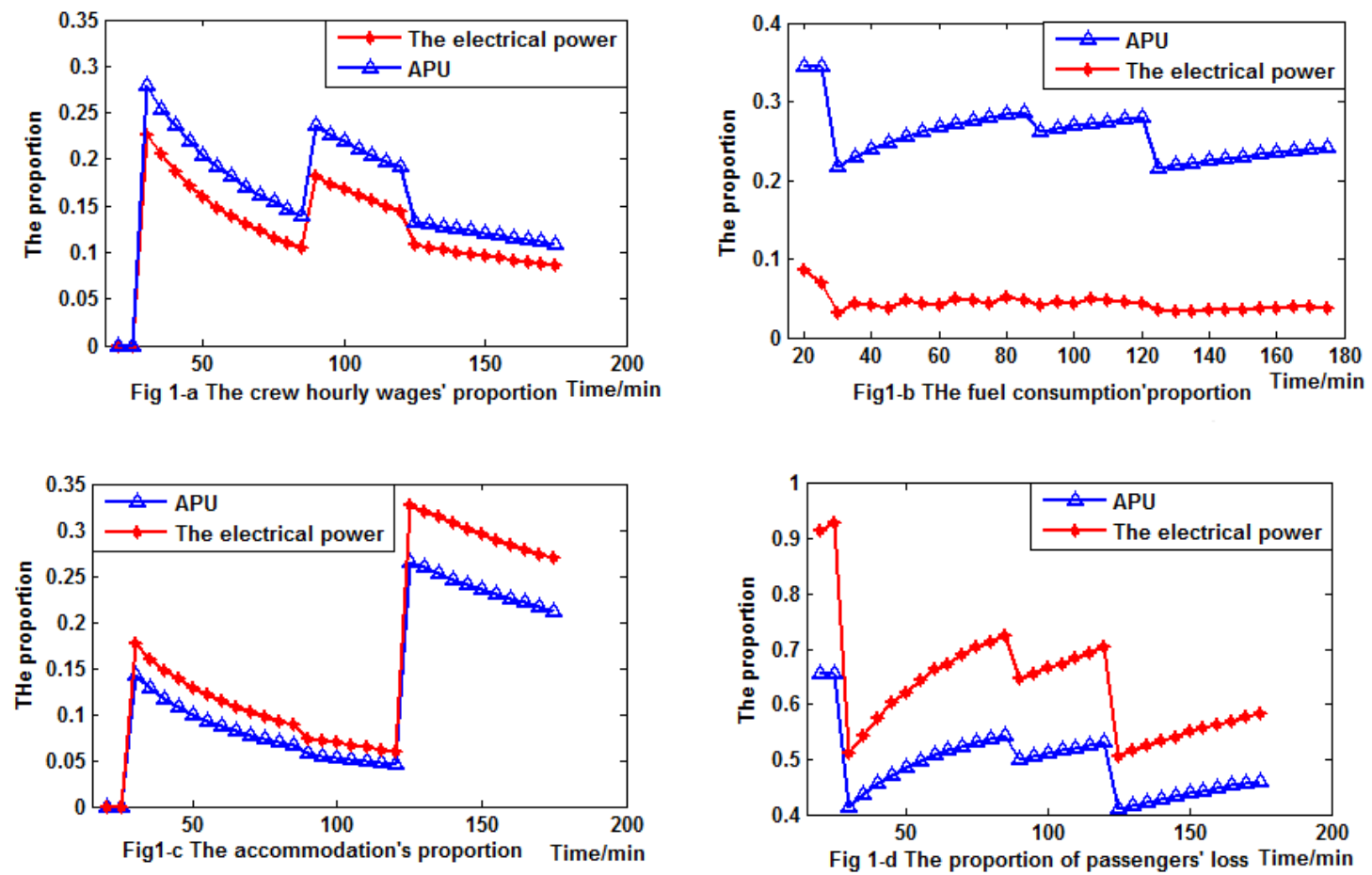

Fig 1 All the proportion of the total cost

Fig 1-a is the trend of the crew hourly wages along with the time. At the first phrase, the figures are the same.it is because the cost of this part is zero before this. Then the hourly wages of crew show a periodic change because of the billing ways. And the proportion of the APU is more than the electrical power.

Fig 1-b is the proportions of the energy cost. The airport charges for the $400 \mathrm{~Hz}$ electrical power or APU. From the figure we can see, this trend variation is different from the passengers' loss. When $\mathrm{t}=15 \mathrm{~min}$, there is an inflexion because the hourly wages of crew began to billing, which leads to energy cost rate rising after fall. As well the electrical power cost is much less than the cost of APU and the trend is much gently, which also explain the proportion of the electrical power has huge economic advantages than APU.

Fig 1-c is the proportion of accommodation for passengers. In the first 15 minutes, energy cost' proportion is very low because of the hourly wages of crew and two power supply ways. So the proportion of accommodation is more than $15 \%$. Then the energy cost and the hourly wages of crew increase so that this proportion decreases. As well, the gap of the proportion of accommodation of the electrical power and APU become bigger along with time.

In the Fig 1-d, the proportion of the passenger is changed along with time. At the first stage, the proportion of passengers' loss is very high. And the power cost is very low. But along with the time, the former decreases badly to the lowest. And there is an inflexion point on the figure. Then the passenger loss is proportional to the time. the proportion of passenger when the aircraft is provided power by APU is less than the same proportion when aircraft is provided power by the electrical power( $C_{\text {passenger }}^{r}<C_{\text {passenger }}$ ).that is because of the total loss of the electrical power is less than APU.

\section{Conclusion}

This paper analyzes cost of flight ground-holding cost in detail and structure the ground-holding cost model respectively according to different power supply ways. From the analysis we can see that, the electrical power has huge economic advantages than APU. Therefore, for the airlines or the passengers, it has very practical meaning to take ground-holding power supply cost into consideration. 


\section{Acknowledgement}

This work is supported by the National ATC Research Found(GKG201403001).

\section{References}

[1] Terrab M. Ground-holding strategies for air traffic control [D]. Massachusetts:Massachusetts Institute of Technology, 1990.

[2] Vrans P B M, Bertsimas D, Odoni A R. Dynamic ground-holding polices for a network ofairports[J]. Transportation Science, 1994, 28(4):275-29

[3] Yu jing, Fu qiang. Cost Modules Researches in Multi-airport Ground-holding Problem [J] Journal of University of Electronic Science and Technology of China,2007,3 (36):598-600

[4] Hu Minghua, Qian Aidong. Research of Multi-airport ground-holding problem model [J]. Journal of Nanjing University of Aeronautics \& Astronautics,2000,32(5):586-590

[5] Xue Xiaohao, Li Xiong. Cost Analysis of Flight Delays and Simulation in Ground-holding Model[J]. Journal of Nanjing University of Aeronautics \& Astronautics,2006,38(1):115-120

[6] Zhao Wenzhi, Liu Bo. Evaluation Method Study for Flight DelayCost[J].Journal,2011,9(1):5-9

[7] CCAR-93TM.China's civil aviation air traffic management rule[S] 